\title{
Mucoadhesive Oral Wound Rinse
}

National Cancer Institute

\section{Source}

National Cancer Institute. Mucoadhesive Oral Wound Rinse. NCI Thesaurus. Code C95730.

A viscous, oral hydrogel rinse intended for the management of oral mucositis/stomatitis.

Mucoadhesive oral wound rinse consists of purified water, glycerin, benzyl alcohol, sodium saccharin, carbomer homopolymer A, potassium hydroxide, citric acid, polysorbate 60 and phosphoric acid. Upon garg ling and rinsing with this solution, it forms a soothing protective hydrogel coating over the oral mucosa, thereby potentially preventing or reducing chemotherapy-induced mucositis. 